\title{
INVESTIGATION OF THE DYNAMIC LOADING OF A BODY OF PASSENGER CARS DURING TRANSPORTATION BY RAIL FERRY
}

\author{
Alyona Lovska \\ Department of Wagons \\ Ukrainian State University of Railway Transport \\ 7 Feierbakh sq., Kharkiv, Ukraine, 61050 \\ alyonaLovskaya.vagons@gmail.com \\ Oleksij Fomin \\ Department of Wagons and Wagonriage Facilities \\ State University of Infrastructure and Technology \\ 9 Kyrylivska str., Kyiv, Ukraine, 04071 \\ fomin1985@ukr.net \\ Anatoliy Horban \\ Department of Humanitarian Disciplines \\ State University of Infrastructure and Technology \\ 9 Kyrylivska str., Kyiv, Ukraine, 04071 \\ Feklo15@gmail.com \\ Valentyna Radkevych \\ Institute of vocational education and training of \\ the National academy of educational science of Ukraine \\ 98-a Vito-Litovskyi side street, Kyiv, Ukraine, 03045 \\ mrs.radkevich@gmail.com \\ Pavel Skok \\ Department of Economics, Marketing and Business Administration \\ State University of Infrastructure and Technology \\ 9 Kyrylivska str., Kyiv, Ukraine, 04071 \\ 6563324@gmail.com \\ Inna Skliarenko \\ Senior Researcher of Research Sector \\ State University of Infrastructure and Technology \\ 9 Kyrylivska str., Kyiv, Ukraine, 04071 \\ innakdavt@ukr.net
}

\footnotetext{
Abstract

To ensure the safety of passenger carriages by rail ferries, mathematical modeling of dynamic loading is performed. The accelerations are determined as components of the dynamic load acting on the body of a passenger car. This takes into account the actual hydrometeorological characteristics of the water area of the railway ferry. The calculations are made in relation to the railway ferry "Mukran", which moves the Baltic Sea. The model takes into account that the car body is rigidly fixed relative to the deck and during the oscillations of the railway ferry follows the trajectory of its movement. The solution of the mathematical model is implemented in the Mathcad software environment using the Runge-Kutta method. It is established that the maximum value of the acceleration acting on the car body is $1.8 \mathrm{~m} / \mathrm{s}^{2}$.

Determination of the dynamic loading of the passenger car body during transportation by sea is also carried out by computer simulation. The calculations were carried out in the CosmosWorks software package using the finite element method. Numerical values and acceleration distribution fields are obtained relative to the carriage body structure of a passenger car.

A modal analysis of the car body during transportation by rail ferry is carried out. The numerical values of the critical frequencies and waveforms are obtained.
} 
To check the adequacy of the developed models, a calculation is made according to the Fisher criterion. It is established that the hypothesis of adequacy is not rejected.

The research will contribute to the creation of recommendations on the safety of passenger carriages by railway ferries, as well as the manufacture of their modern structures in terms of car-building enterprises.

Keywords: passenger car, dynamic loading, body acceleration, loading modeling, modal analysis, rail-ferry transportation.

DOI: 10.21303/2461-4262.2019.00950

\section{Introduction}

Creating competition in the market of transport services leads to the commissioning of combined transport systems. In countries having access to marine waters, rail-ferry traffic has become widespread. The peculiarity of such transportation is the possibility of following the wagons by sea on special vessels - railway ferries. At present, transportation by sea is carried out not only freight, but also passenger cars (Fig. 1).

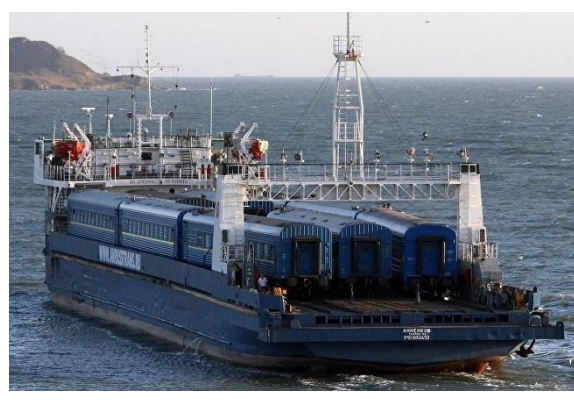

$a$

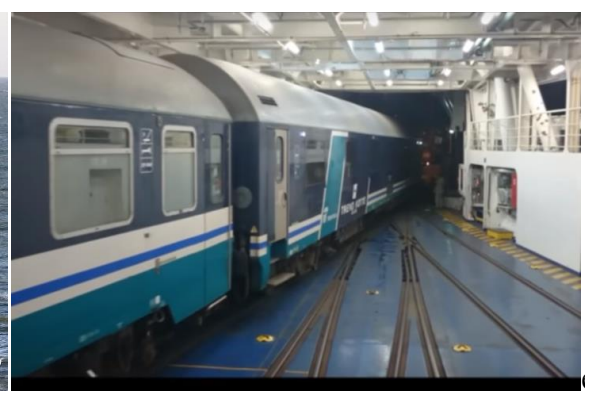

$b$

Fig. 1. Transportation of passenger cars on rail ferries by sea: $a$ - "Annenkov" ferry (Sea of Azov); $b$ - Fata Morgana ferry (Strait of Messina)

In order to ensure the stability of the car bodies in transit by sea, they are fixed relative to the decks. For this purpose, special multi-current funds are used. On the bodies of passenger cars of the last years of construction, special brackets are provided for interacting with fastening means (Fig. 2).

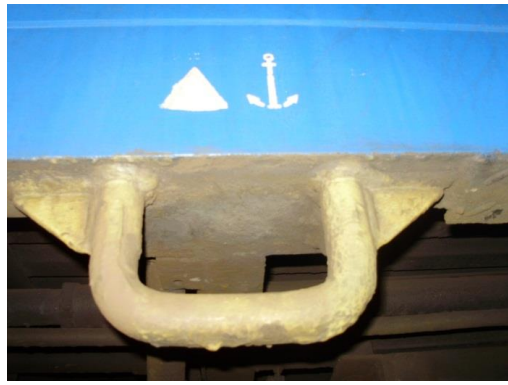

$a$

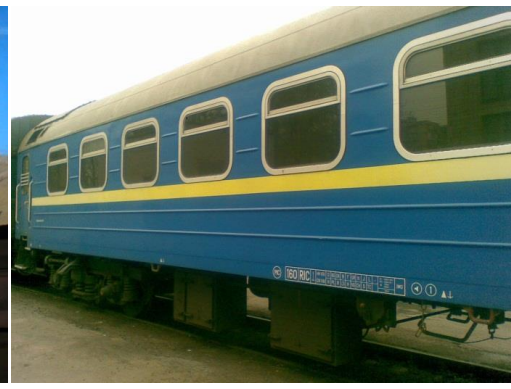

$b$

Fig. 2. Staples for fixing the passenger car body relative to the deck: $a$ - fastening to the car body; $b$ - placement along the car

To ensure the safety of transportation of cars by sea, it is important to study their dynamic loading [1-3]. Analysis of the existing regulatory and technical documentation allows to conclude that the issue of dynamic loading of bodies of passenger cars during carriage by rail ferries has not yet been adequately covered $[4,5]$.

The aim of the article is to highlight the features of modeling the dynamic loading of the body of a passenger car when transported on a railway ferry. To achieve this aim, the following tasks are defined: 
- to carry out mathematical modeling of the dynamic loading of the body of a passenger car during transportation on a railway ferry;

- to carry out computer simulation of the dynamic loading of the body of a passenger car when transported on a railway ferry;

- to conduct a modal analysis of the body of a passenger car when transported on a railway ferry;

- to verify the developed models of the dynamic loading of the body of a passenger car when transported on a railway ferry.

\section{Mathematical modeling of the dynamic loading of the passenger car body during transpor- tation by rail ferry}

In order to determine the dynamic loads acting on the body of a passenger car when transported by sea, a mathematical model has been drawn up that takes into account the angular displacements of the railway ferry relative to the longitudinal axis (roll) [6, 7]. This type of oscillatory process was chosen for determining, because it has the greatest impact on the strength and stability of the body relative to the deck [8-10]. The design scheme is shown in Fig. 3

$$
\frac{D}{12 \cdot g} \cdot\left(B^{2}+4 \cdot z_{g}^{2}\right) \cdot \ddot{q}+\left(\Lambda_{\theta} \cdot \frac{B}{2}\right) \cdot \dot{q}=p^{\prime} \cdot \frac{h}{2}+\Lambda_{\theta} \cdot \frac{B}{2} \cdot \dot{F}(t),
$$

where $q$ - the generalized coordinate, corresponds to the angular displacement around the longitudinal axis $X$ of the railway ferry with the cars placed on it; $D$ - weight displacement; $B$ - width; $h$ - side height; $\Lambda_{\theta}$ - coefficient of resistance to oscillations; $z_{g}$-coordinate of the gravity center; $p$ '- wind load; $F(t)$ - the law of action of force that excites the movement of a railway ferry with car bodies placed on its decks.

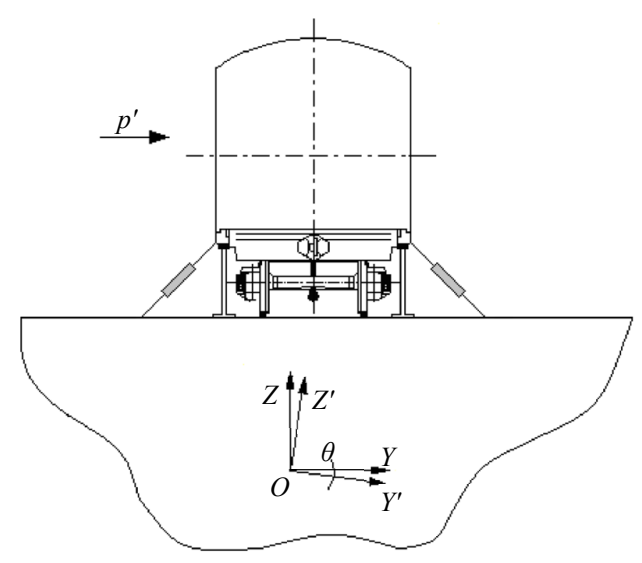

Fig. 3. The design scheme for determining the dynamic loading of the body of a passenger car

The impact of sea waves on the body of a railway ferry with cars placed on board was not taken into account. The model takes into account the dissipative component that occurs when the railway ferry oscillates under sea conditions. Also, the model takes into account the course angles of the sea wave in relation to the body of the railway ferry and the wind load on the surface projection.

The frequency of the sea wave is determined taking into account the course angle to the hull of a railway ferry with cars placed on its decks [8]:

$$
\omega=\frac{2 \pi \cdot v}{k_{\lambda} \cdot L \cdot \cos \chi}
$$

where $v$ - speed of the railway ferry; $k_{\lambda}$ - coefficient depending on the shape of the ship's contours; $\chi$ - heading angle of the wave relative to the body of the railway ferry. 
In compiling the model, the trochoidal law of motion of a disturbing action (sea wave) on a railroad ferry with car bodies placed on its decks was taken into account [11].

The input parameters of the model are the technical characteristics of the railway ferry and bodies of passenger cars, as well as the hydrometeorological characteristics of the water area. The calculations were carried out in relation to the railway ferry of the type "Mukran" [12, 13], which moves the water area of the Baltic Sea. Hydrometeorological characteristics of the sea area are determined according to the data given in [14].

The solution of differential equations is carried out using the Runge-Kutta method in the MathCad software environment [15, 16].

To solve equation (1), let's the standard function $\operatorname{rkfixed}(Y 0, t n, t k, n, Q)$ embedded in Math$\mathrm{Cad}$. The vector $Y 0$ contains the initial conditions. The values $t n$ and $t k$ determine the initial and final variable of integration, $n$ - fixed number of steps, $Q$ - a symbol vector [17].

The transition from second order differential equations (1) to first order differential equations (3) is carried out to apply standard algorithms for solving the system in Mathcad.

$$
\begin{gathered}
Q(t, y)=\left|\begin{array}{c}
y_{2} \\
\frac{p^{\prime} \cdot \frac{h}{2}+\Lambda_{\theta} \cdot \frac{B}{2} \cdot \dot{F}(t)-\left(\Lambda_{\theta} \cdot \frac{B}{2}\right) \cdot y_{2}}{\frac{D}{12 \cdot g} \cdot\left(B^{2}+4 \cdot z_{g}^{2}\right)}
\end{array}\right| \\
Z=\operatorname{rkfixed}(Y 0, t n, t k, n, Q) .
\end{gathered}
$$

The total amount of acceleration acting on the body of a passenger car when transported by rail ferry is determined

$$
\ddot{q}(t)=\ddot{q}_{R E G}(t)+g \cdot \sin \theta,
$$

where $\ddot{q}_{R E G}(t)$ - acceleration, which acts in relation to the regular location of the car on the deck of the railway ferry; $\theta$ - roll angle of the rail ferry.

The results of the calculation makes it possible to determine the numerical values of the accelerations, as components of the dynamic load acting on the body of a passenger car when transported on a railway ferry (Fig. 4). From Fig. 4, it can be seen that the largest value of accelerations acts on the car body at course angles of the wave relative to the body of the railway ferry 600 and 1200 and is about $1.8 \mathrm{~m} / \mathrm{s}^{2}$. That is, it exceeds the magnitude of the accelerations acting on the bodies of passenger cars during operation relative to the main routes $[4,5]$.

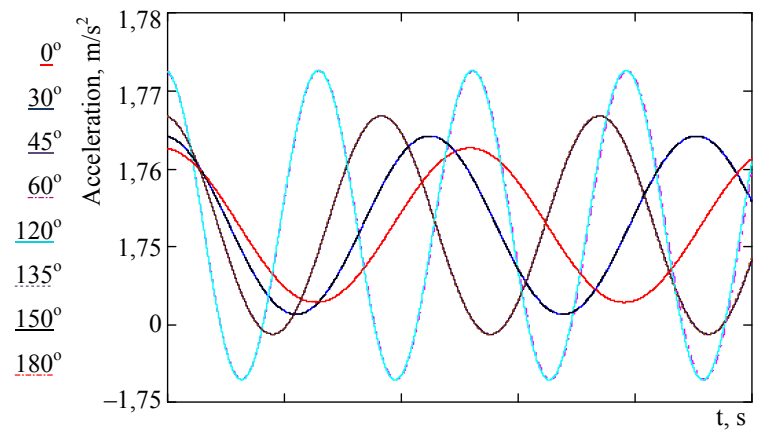

Fig. 4. Acceleration acting on the body of a passenger car when transported by rail ferry

\section{Computer simulation of the dynamic loading of the body of a passenger car when trans- ported by rail ferry}

In order to determine the fields of distributions of accelerations with respect to the supporting structure of the body of a passenger car, computer modeling of dynamic loading is carried out 
during carriage on a railway ferry. For this purpose, a spatial model of the body of a passenger car in the environment of SolidWorks software (Fig. 5) is created.

In drawing up the model, structural elements are taken into account, which rigidly interact with each other.

The calculation is carried out using the finite element method implemented in the CosmosWorks software package [18]. In the compilation of the finite element model, spatial isoparametric tetrahedra are used. The optimal number of elements is determined by the graphic-analytical method. The number of model nodes is 183393 , the elements -520475 . The maximum element size is $80 \mathrm{~mm}$, and the minimum $-16 \mathrm{~mm}$. The percentage of elements with an aspect ratio of less than three -15.1 , more than ten -56 . The minimum number of elements in a circle is 12 ; the ratio of the increase in the size of elements is 1.8 .

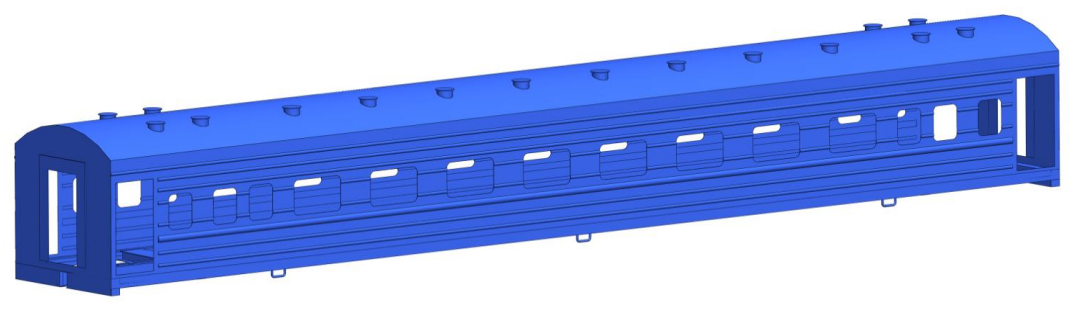

$a$

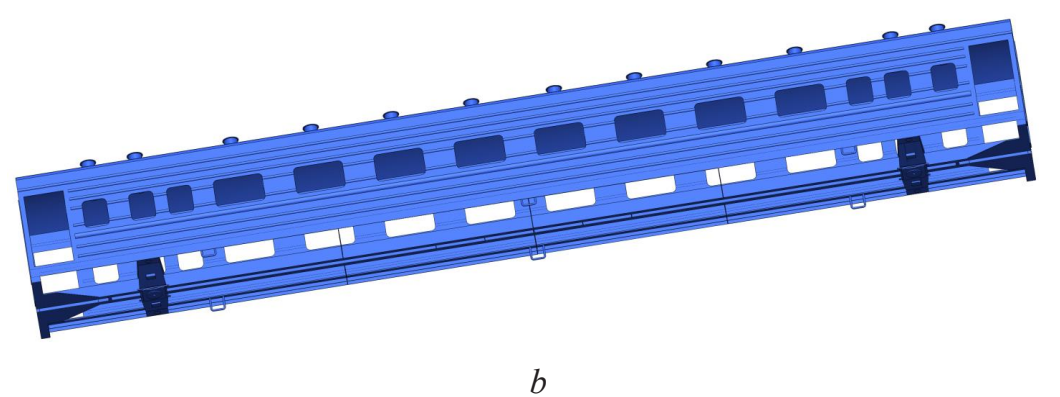

Fig. 5. Spatial model of the passenger car body: $a$ - side view; $b$ - bottom view

In compiling the model, it was taken into account that the body of the car is subject to a vertical static load, $P_{v}^{s t}$, a wind $\mathrm{P}_{w}$ force, as well as efforts from radar chain screeds $\mathrm{P}_{c s}$ (Fig. 6). Since the chain ties have a spatial distribution, the efforts that will act on the body through them broke up into components. This takes into account the angles of placement of the chain tie in space.

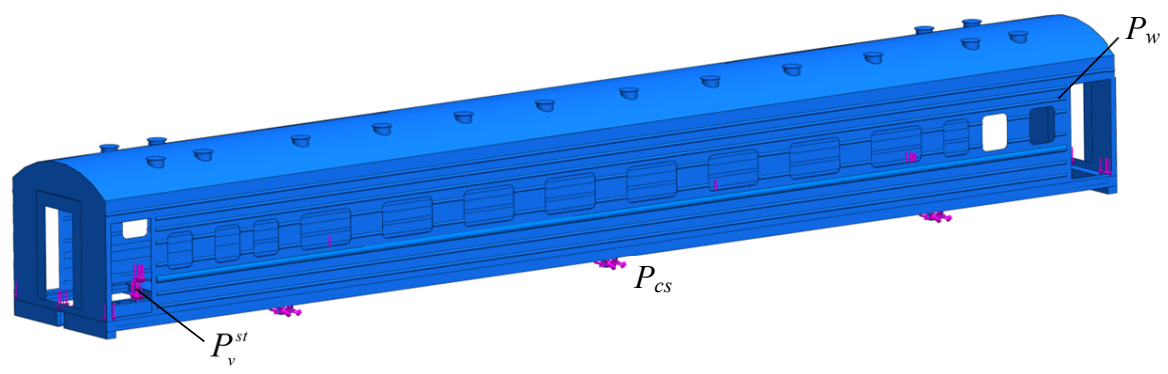

Fig. 6. The design scheme for determining the dynamic loading of the body of a passenger car during carriage by rail ferry

The fastening of the model is carried out in the areas of the body support on the chassis of the car, as well as in the installation zones of the stop-jacks. To do this, the model installed lining, the diameter of which is identical to the diameter of the working part of the mechanical stop-jack (Fig. 7). Carbon steel st. 3 are used as the material of the body structure. 


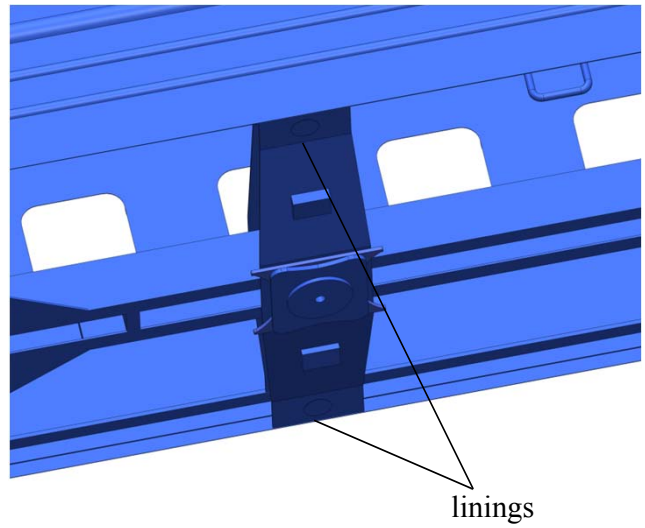

Fig. 7. Placing linings to simulate the bearing of the car body on the mechanical stop-jacks

The calculation results are shown in Fig. 8.

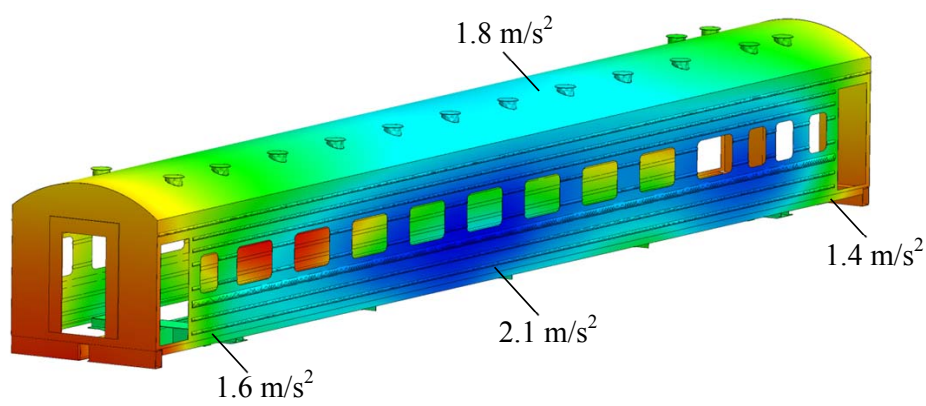

Fig. 8. The distribution of the fields of acceleration relative to the supporting structure of the body of the passenger car

So the maximum values of accelerations are concentrated in the middle part of the side wall of the car body and are $2.1 \mathrm{~m} / \mathrm{s}^{2}$. In the areas of the body supporting the mechanical stop-jacks, the acceleration is about $1.4 \mathrm{~m} / \mathrm{s}^{2}$.

\section{Modal analysis of the body of a passenger car when transported by rail ferry}

A modal analysis is performed to determine the critical frequencies and vibration modes of the passenger car body. The calculations are carried out in the CosmosWorks software package. The numerical values of the critical oscillation frequencies are given in Table $\mathbf{1}$.

Table 1

Numerical values of the critical frequencies of oscillations of the body of a passenger car when transported by rail ferry

\begin{tabular}{ccc}
\hline Oscillation form & Frequency, $\mathbf{r a d} / \mathbf{s}$ & Frequency, Hz \\
\hline 1 & 54.4 & 8.7 \\
2 & 107.1 & 17.1 \\
3 & 129.5 & 20.6 \\
4 & 135.6 & 21.6 \\
5 & 149.8 & 23.8 \\
6 & 163.2 & 25.9 \\
7 & 176.6 & 28.1 \\
8 & 208.5 & 33.2 \\
9 & 211.7 & 33.7 \\
10 & 219.7 & 34.9
\end{tabular}


Calculations show that critical frequencies are within acceptable limits. Also, the results of the calculation make it possible to determine the main forms of vibration of the body of a passenger car. For an example Fig. 9 shows the main forms of vibration of the body of a passenger car when transported by rail ferry. The results are shown in a scale of deformations of 1:50. Transparent color specified initial state of the structure.

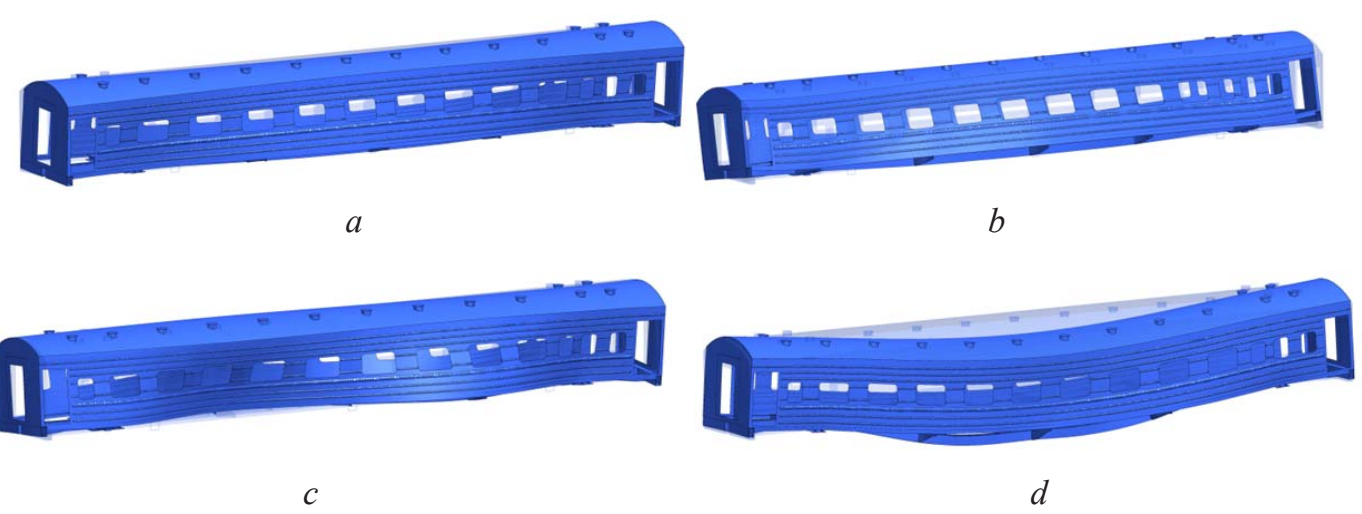

Fig. 9. Forms of oscillations of the body of a passenger car when transported by rail ferry: $a$ - the first form; $b$ - the second form; $c$ - the third form; $d$ - the fourth form

The resulting vibration modes allow to determine the most loaded areas of the car body and when designing modern passenger car structures to take into account these deformations.

\section{Verification of the developed models of the dynamic loading of the body of a passenger car during transportation on a railway ferry}

For verification of the developed models, a calculation is made according to the Fisher criterion $[19,20]$.

$$
F_{p}=\frac{S_{a d}^{2}}{S_{y}^{2}},
$$

where $S_{a d}^{2}$-adequacy dispersion; $S_{y}^{2}$ - reproducibility dispersion.

The variance of adequacy was according to the formula

$$
S_{a d}^{2}=\frac{\sum_{i=1}^{n}\left(y_{i}-y_{i}^{c}\right)}{f_{i}},
$$

where $y_{i}^{c}$ - calculated value of the value obtained by modeling; $f_{i}$ - number of degrees of freedom.

$$
f_{i}=N-q
$$

where $N$ - the number of experiments in the planning matrix; $q$ - the number of coefficients of the equation.

The dispersion of reproducibility is determined by the formula

$$
S_{y}^{2}=\frac{1}{N} \sum_{i=1}^{n} S_{i}^{2}
$$

where $S_{i}^{2}$ - dispersion at each point where parallel experiments are conducted.

The required number of static data is recognized by Student's criterion [21, 22]. 


$$
n=\frac{t^{2} \cdot \sigma^{2}}{\delta^{2}}
$$

where $t$ - tabular value of the Student's criterion; $\sigma$ - average deviation of a random variable; $\delta^{2}-$ absolute error of the measurement result.

The input parameter of the model is the roll angle of the rail ferry with the cars placed on it, and the output is acceleration. The calculation results are shown in Fig. 10. The trend line equation, which describes the results of mathematical modeling in Fig. 10 marked $y_{M}$, and computer $-y_{C}$.

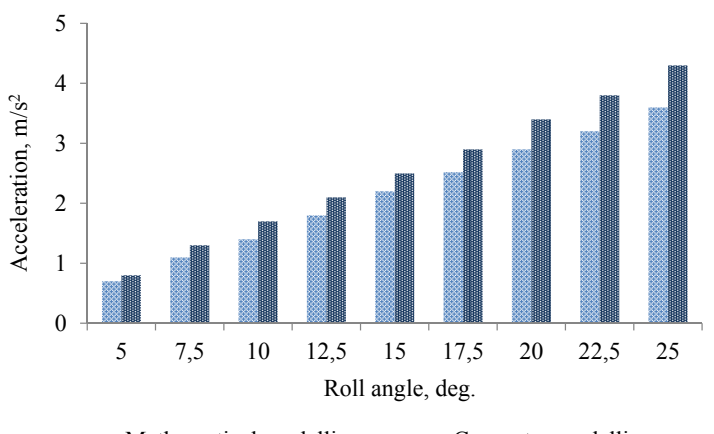

Fig. 10. The results of modeling the dynamic loading of the body of a passenger car when transported by rail ferry

The discrepancy between the results of mathematical and computer modeling in percent is shown in Fig. 11.

The maximum discrepancy in this case is about $18 \%$ at a roll angle of rail ferry 100 , the smallest $-12 \%$ for a roll angle of 150 .

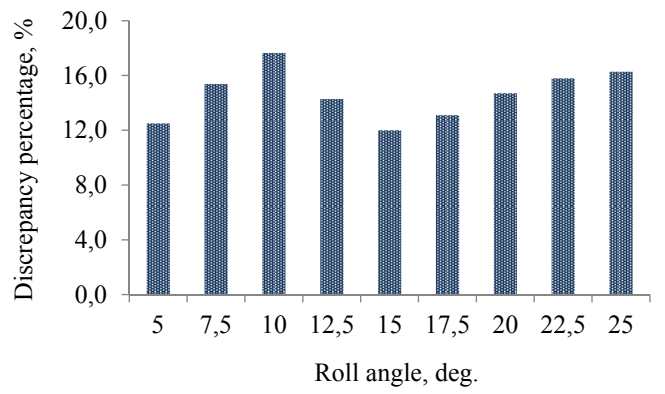

Fig. 11. Discrepancy between the results of mathematical and computer modeling

It is established that with dispersion of reproducibility $S_{\mathrm{y}}^{2}=0.97$ and dispersion of adequacy $S_{a d}^{2}=1.38$, the actual value of the criterion $F_{\mathrm{p}}=1.4$, which is less than the tabular value of the criterion $\left(F_{t}=3.29\right)$. That is, the hypothesis of adequacy is not disputed.

\section{Discussion of the research results of the dynamic loading of the body of a passenger car when transported by rail ferry}

Studies have allowed to determine the dynamic loading of the body of a passenger car when transported by rail ferry. It has been established that the largest value of accelerations acts on the car body at course angles of the wave relative to the body of the railway ferry 600, as well as 1200 , and is about $1.8 \mathrm{~m} / \mathrm{s}^{2}$. That is, it exceeds the magnitude of the accelerations acting on the bodies of passenger cars during operation with respect to trunk routes.

The results of computer simulation show that the maximum acceleration values are concentrated in the middle part of the side wall of the car body and are $2.1 \mathrm{~m} / \mathrm{s}^{2}$. At the same time, in the areas of body support for mechanical stop-jacks, the acceleration was about $1.4 \mathrm{~m} / \mathrm{s}^{2}$. 
The developed models are verified by the Fisher criterion.

However, it is important to note that when modeling dynamic loading it is taken into account that the car body is rigidly fixed relative to the deck and carries out movement with it. That is, there are no possible own movements of the car body. Also, the model takes into account the constant speed of the railway ferry.

Further studies need to take into account these limitations. In addition, it is necessary to take into account the stochastic parameters of the disturbing action in the model.

An important stage in the development of these studies is to conduct a physical experiment of dynamic loading of bodies of passenger cars.

These studies will create recommendations for the safe operation of passenger cars in the international rail-water communication. Also, the results will contribute to the creation of modern passenger car structures in the conditions of car-building enterprises.

\section{Conclusions}

Mathematical modeling of the dynamic loading of the body of a passenger car during transportation on a railway ferry is carried out. It has been established that the largest value of accelerations acts on the car body at course angles of the wave relative to the body of the railway ferry 600 and 1200 and is about $1.8 \mathrm{~m} / \mathrm{s}^{2}$. So the magnitude of the accelerations that acts on the body of a passenger car exceeds the acceleration acting during operation relative to the main tracks;

Computer modeling of the dynamic loading of the passenger car body during transportation on the railway ferry is carried out. The maximum values of accelerations are concentrated in the middle part of the side wall of the car body and are $2.1 \mathrm{~m} / \mathrm{s}^{2}$. In the areas of the body supporting the mechanical stop-jacks, the acceleration was about $1.4 \mathrm{~m} / \mathrm{s}^{2}$;

A modal analysis of the passenger car body was carried out during carriage by rail ferry. The calculation results showed that the critical frequencies are within acceptable limits;

Models of dynamic loading of the body of a passenger car during transportation on a railway ferry have been developed.

It is established that with dispersion of reproducibility $S_{\mathrm{y}}^{2}=0.97$ and dispersion of adequacy $S_{a d}^{2}=1.38$, the actual value of the criterion $F_{\mathrm{p}}=1.4$. That is, the table value of the criterion exceeds the calculated one. So the hypothesis of adequacy is not disputed.

The research will contribute to the creation of recommendations on the safety of passenger carriages by railway ferries, as well as the manufacture of their modern structures in terms of car-building enterprises.

\section{References}

[1] Myamlin, S., Lunys, O., Neduzha, L., Kyryl'chuk, O. (2017). Mathematical Modeling of Dynamic Loading of Cassette Bearings for Freight Cars. Transport Means, 973-976.

[2] Fomin, O. V., Burlutsky, O. V., Fomina, Yu. V. (2015). Development and application of cataloging in structural design of freight car building. Metallurgical and Mining Industry, 2, 250-256.

[3] Lovskaya, A., Ryibin, A. (2016). The study of dynamic load on a wagon-platform at a shunting collision. Eastern-European Journal of Enterprise Technologies, 3 (7 (81)), 4-8. doi: http://doi.org/10.15587/1729-4061.2016.72054

[4] GOST 34093-2017. Vagonyi passazhirskie lokomotivnoy tyagi. Trebovaniya k prochnosti i dinamicheskim kachestvam (2017). Moscow: Standartinform, 45.

[5] EN 12663-1:2010: Railway applications - Structural requirements of railway vehicle bodies - Part 1: Locomotives and passenger rolling stock (and alternative method for freight wagons) (2010). BSI, 39.

[6] Fomin, O., Lovska, A., Kulbovskyi, I., Holub, H., Kozarchuk, I., Kharuta, V. (2019). Determining the dynamic loading on a semi-wagon when fixing it with a viscous coupling to a ferry deck. Eastern-European Journal of Enterprise Technologies, 2 (7 (98)), 6-12. doi: http://doi.org/10.15587/1729-4061.2019.160456

[7] Fomin, O., Lovska, A., Masliyev, V., Tsymbaliuk, A., Burlutski, O. (2019). Determining strength indicators for the bearing structure of a covered wagon's body made from round pipes when transported by a railroad ferry. Eastern-European Journal of Enterprise Technologies, 1 (7 (97)), 33-40. doi: http://doi.org/10.15587/1729-4061.2019.154282

[8] Shimanskiy, Yu. A. (1963). Dinamicheskiy raschet sudovyih konstruktsiy. Leningrad, 444.

[9] Makov, Yu. L. (2007). Kachka sudov. Kaliningrad, 321. 
[10] Zemlezin, I. N. (1970). Metodika rascheta i issledovaniya sil, deystvuyuschih na vagon pri transportirovke na morskih paromah. Moscow: Transport, 104.

[11] Lugovskiy, V. V. (1976). Dinamika morya. Leningrad: Sudostroenie, 199.

[12] Klochenko, N. (1988). Parom “Klaypeda”, Morskoy flot, 5, 27-31.

[13] Morskoy zheleznodorozhno-avtomobilno-passazhirskiy parom «Petersburg» (2016). Available at: http://www.korabli.eu/galleries/oboi/grazhdanskie-suda/petersburg

[14] Veter i volnyi v okeanah i moryah: spravochnyie dannyih (1974). Leningrad: Transport, 359.

[15] Kiryanov, D. V. (2012). Mathcad 15 / Mathcad Prime 1.0. Saint Petersburg: BHV-Peterburg, 432.

[16] Okorokov, A., Fomin, O., Lovska, A., Vernigora, R., Zhuravel, I., Fomin, V. (2018). Research into a possibility to prolong the time of operation of universal open top wagon bodies that have exhausted their standard resource. Eastern-European Journal of Enterprise Technologies, 3 (7 (93)), 20-26. doi: http://doi.org/10.15587/1729-4061.2018.131309

[17] Dyakonov, V. (2000). MATHCAD 8/2000: spetsialnyiy spravochnik. Saint Petersburg: Piter, 592.

[18] Alyamovskiy, A. A. (2015). SolidWorks Simulation. Inzhenerniy analiz dlya professionalov: zadachi, metody, rekomendacii. Moscow: DMK Press, 562.

[19] Rudenko, V. M. (2012). Matematychna statystyka. Kyiv: Tsentr uchbovoi literatury, 304.

[20] Matalyckiy, M. A., Hackevich, G. A. (2017). Teoriya veroyatnostey i matematicheskaya statistika. Minsk: Vysheyshaya shkola, 591.

[21] Kosmin, V. V. (2007). Osnovyi nauchnyih issledovaniy. Moscow: GOU “Uchebno-metodicheskiy tsentr po obrazovaniyu na zheleznodorozhnom transporte", 271.

[22] Kalinina, V. N. (2015). Teoriya veroyatnostey i matematicheskaya statistika. Moscow: Izdatelstvo Yurayt, 472.

Received date 20.06.2019

Accepted date 09.07.2019

Published date 31.07.2019
(C) The Author(s) 2019

This is an open access article under the CC BY license (http://creativecommons.org/licenses/by/4.0). 